\title{
The Missing and Return of Current Setback Education
}

\author{
Daoxun Wang \\ Huanghe Science and Technology College \\ Zhengzhou, China
}

\begin{abstract}
The setback education is a way of education that letting educatee get frustration on the physical and mental to promote the comprehensive quality represented by physical quality and psychological quality improve. At present, setback education in our country has several issues, such as the constantly missing of setback education in school education and in family education and without proper guidance in society. To this, we should carry out education policy, correct the concept of family education and rich activities of society education to strengthen setback education and make it return.
\end{abstract}

Keywords-setback education; Form and Content; Rake up; Missing and return

\section{INTRODUCTION}

The term setback education is usually applied in the field of literary works or entertainment. The "setback" in setback education can be understood as pain or disaster, but cannot simply treat it as pain or disaster. Broadly speaking, the setback is a process that people have frustration both in physical and psychological during their growth and whole life. Setback education emphasizes what we can learn from the suffering of frustration, not just accept it. The setback education is a way of education that letting educatee get frustration on the physical and mental to promote the comprehensive quality represented by physical quality and psychological quality improve.

The meaning of setback has been discussed both in China and foreign countries. In Heidegger's philosophy of life, a person in the real world is always painful so he has to find his home, and difficulty and confusing are life itself which is natural even couldn't be destroyed forever. Mencius said, god will drop responsibility on this person by frustrating, hardship, hungering and emptying its body and blowing to its nature to stimulate its ability. Professor Wenxuan Cao suggests, each era has its suffering and feature so the teenagers of each era are also different. Facing the increasing material condition of society, we should teach students to face suffering more bravely and translate it into motivation. At the same time we shouldn't show off suffering but face and eliminate it to set up a strong personality with care and comfort, sympathy and help.

\section{The Present Situation of the CURREnt Setback EDUCATION}

Along with the lack of setback education in our country, the comprehensive quality of people is declining. At present, there are a lot of problems of setback education in school education, family education and society.

\section{A. The Constantly Lack of Setback Education in School}

At present, throughout the way of education in our country, general knowledge courses are still in the main and dominate status. Most of the education focus too much on general knowledge courses that there are few opportunities for students to have mental quality exercise and physical activities, let alone specialized setback education. In this kind of learning dominated by general knowledge courses, the greatest difficult that students will encounter in the learning process is probably the psychological burden due to the less ideal general knowledge course result without receiving relevant setback education. At present, there are no specialized courses and education means to give students setback education in every stage of education in our country. Although many schools in China have set up a counseling agency and related psychological courses, the emphasis of them is not enough, the investment is relatively small and the allocation of resources is relatively weak, which lead to constantly lack of setback education in school education.

\section{B. The Constantly Lack of Setback Education in Family}

With the rapid development of economy in our country, the national overall wealth continuously improve, add up with the deepening of the reform of education and modern education idea transformation, most people live a life with few setback education or even without it, especially after 90 and after 00 who were mostly being waited on hand and foot in the process of their growth. At the same time, when parents teach their children, they tend to focus on their academic performance or if children can master certain specialty. Currently, most adults have experienced more or less difficult, therefore they dote on their children too much instead of spending too much money on setback education. They would rather let their children to attend after-school classes and talents training, such as all kinds of cram school and training of piano, computer and dancing. Of course, we shouldn't blindly against special education, but mention setback education to them in the process of their growth. 
Most parents want their children to receive school education and a variety of special education which is closely related to the setback education that the parents received in their childhood. Also it's a major cause of the continuously missing of setback education in family education.

\section{Setback Education without Proper Guidance in Society}

After finished school education people enter into society. The suffering in society begins when they leave school, such as the employment problem. For those who have not experienced setback education for a long time or received relatively few, they can't grasp the nettle and find ways to overcome the difficulties as the one who received setback education. What they always do is abandon themselves, or even some of them lose faith in society. However, without proper guidance in society setback education is unable to realize the reality and possibility in society.

\section{The VAlue And SignificAnCE OF SETbaCK EDUCATION}

Setback education has important significance to the improvement of quality of people, and it can improve people's physical quality, psychological quality and make people more adapt to social development. The lack of setback education leads to many problems: the ideological education in our country is not comprehensive; the ability of suffering setback of people drops a lot; the perceptivity of happiness of people drops a lot. Therefore, it is of great significance to strengthen setback education.

\section{A. Improve Body Quality}

The frustration on body is also an important content in setback education, and it can effectively improve people's physical quality. The improvement of people's physical quality is closely related to exercises, the suffering of body can be treated as the largest setback body suffered when they receive setback education. Exercise in general is movement accumulated in one's body to strengthen people's organizations and organ functions and improve the body adaptability to changes of work intensity and the outside world by accumulating. Relatively simply physical exercise for the suffering when people feel frustrated can make themselves know more about their body and what their body need and how to make their body stronger. At the same time, the setback education on body will make people cherish and care for their body, better play their body functions and enhance their physical quality.

\section{B. Improve Psychological Quality}

For those people who didn't receive setback education, when they experience setbacks, they always feel lost and desperate, they not only with relatively low psychological quality but also lack of the courage to face difficulty and setback or the determination of solving problems. While for people who received setback education, they often grow up in setbacks. When they encountered difficulties and setbacks, they can bear them in a proper way with good psychological quality and be more firm in solving these difficulties.
Therefore, setback education can enhance people's psychological quality.

\section{Help to Adapt to the Society}

With the deepening of the reform and opening up in China, the development of economic and society promote rapidly. When people live in the society with a variety of changes, their personal development often can encounter a lot of opportunities. At the same time, social competition is increasingly fierce. After setback education, it can improve people's physical quality and psychological quality and enable people to confront to the various setbacks and challenges of the society. In this way, people will be more adapt to the rapid development of today's society.

\section{THE URGENCY AND NECESSITY OF RAKING UP SETBACK EDUCATION}

Education mode in our country is largely successful due to the development since the founding of new China, and it also made great achievements, especially the professional performance on academic and research. However, there is no doubt that since 1980's the scientific achievements of China which can influence and change the world are declining. The contribution such as the four great inventions of ancient or even like hybrid rice since the founding of China is less and less which is closely related to the lack of setback education in our country. The urgency and necessity of current setback education is mainly manifested in the following three aspects.

\section{A. The Present Situation of Students}

At present, many students are only children so they often lack of the spirit of working hard, the spirit of bearing hardships, pioneering spirit, fighting spirit and pragmatic spirit. At the same time, influenced by the examinationoriented education thought, some students focus a lot on scores but ignore the quality education. Therefore, it is high time to strengthen the students' setback education.

\section{B. Social Environment}

The bad culture in society will bring serious negative impact on setback education in school. Some bad culture spread by videos or the network such as money worship, personal hedonism and other unhealthy world outlooks lead to the development of multiple values and world outlooks. It makes many teenagers could not study hard caused by the thought that learning is bitter, tired and difficult, add up with the increasing employment pressure. So some teenagers think that studying hard is not necessary. Therefore, it becomes a big problem to be solved for each school at present that how to manage students such as raising the diligent and studious learning attitude ;training students with the spirit of bearing hardships, pioneering spirit, fighting spirit and pragmatic spirit; helping students set up the correct outlook on life and values.

\section{Family Environment}

Modern families only have one child so parents always connive at their child such as lack of discipline, spoil the 
child, take care too much or give in to their child. And it leads to the lack of hard work, pioneering spirit, brave and struggle spirit and pragmatic spirit for the child since he was young. As a result, there is an urgent need for students to have setback education in family education.

Setback is the best university. Setback education does not mean that bearing hardships in the physical aspect or diligent and thrifty in the economic aspect, also not mean that let children back to the past difficult conditions on purpose. Current setback education has taken place in form and content. We should focus on cultivating students' spirit of bearing hardships, pioneering spirit, fighting spirit and hard working spirit so that students will face difficulty bravely and solve them better.

Facing the fierce social change, now we rake up setback education is not back to history. Setback education seems much more precious and it's also the inevitable choice for school, family and society.

\section{MEASURES FOR STRENGTHENING SETBACK EDUCATION}

Society is a school and setback is the best teacher. Without setback education, people will not be able to realize what is difficult and happiness, not really deeply understand society and the patient and avoiding suffering of wisdom. Setback can make a person strive, struggle and mature. Setbacks not only teach people persistence, optimistic, tenacious fight, but also can steel one's will, character and high morale. It can exert potential, increase knowledge, wisdom, talent and becomes the norm in life and the ability of doing things. Setback sometimes is not only a kind of test, but also a kind of culture education teaching people how to break through adversity and overcome difficulties.

\section{A. Play the Primary Role of School Education}

The school is the main place to carry out quality education. To strengthen education, schools should apply the national related education policy and play a leading role in the process of practical teaching. Schools should abandon the traditional exam-oriented education thought tendency and put setback education into professional disciplines and all kinds of classroom teaching in the teaching process. Schools should set up the corresponding scenario to put setback education into school activities, and guide students while demonstrate how to tackle corresponded problems. Only in this way can students foster the good character of hard working, plain lifestyle and bearing hardships, strengthen the psychological quality and improve students' psychological bearing ability of setbacks and suffering. Also, schools should pay attention to the interaction between teachers and students to improve the teaching effect of setback education in school by acting a positive guiding role.

\section{B. Strengthen the Basic Role of Family Education}

Family education has important effect on the growth and development of people. When teenagers receive setback education, family education should be a booster for setback education and show a family effect. On the one hand, parents should treat themselves strictly and set up a learning example for teenagers. On the other hand, parents should change the traditional authoritarian or spoil attitude to change family atmosphere and deal with the corresponding problems in an equal way. Some parents believe that they have to rely on their child so they must love them with all their heart which leads to spoiled in the process of growth. They also don't want their children experience suffering because they think suffering can cause psychological trauma. In addition, there are also some parents hold the view such as "a strict teacher produces outstanding students", "Spare the rod and spoil the child" and "sticks out dutiful son" just because they have been suffered setback education when they were young. These ways of education are not the current setback education we are advocating here.

Therefore, to strengthen setback education, parents should correct their concept of family education so that they could completely abandon the feudal and old traditional way of family education and free students' mind. Parents should pay attention to a kind of unconsciously education. They should constantly optimize the family environment through their own tutelage to provide a good environment for the child.

\section{Rich Social Setback Education Activities}

Strengthening setback education can hold activities which are health for body and mind according to students' psychological characteristics, these activities will give students more opportunities to experience suffering and accept setback education in practice, in order to constantly improve students' psychological enduring capacity when they meet setbacks and difficulties. On the one hand, people should set up the correct view of suffering. Related psychology studies show that the more information of setback education people get, the more positive attitude people will show to face and overcome suffering. People's reactions to the setbacks and their bearing ability depend on both difficult situation itself, and people's perception of setbacks. On the other hand, students should actively participate in social practice activities and improve social adaption ability. Many idealists should actively participate in social practice activities to put themselves into the society due to their lack of social and life experience. They should consciously accept the training of stress coping skills and accumulate experience for handling situational stress from the training to develop the coping skills and the conscious of responsibility of dealing with problems. In this way they will improve their living ability and social adaption ability to achieve the ultimate goal of education suffering. In addition, students should pay attention to psychological counseling and have appropriate psychological vent. Psychological counseling can improve people's psychological quality and promote people's mental health. Psychological education will create a relaxed and catharsis opportunity to enable people to freely express their repressed emotion and relax nerves, thus improve the ability of suffering. 


\section{CONCLUSION}

Max said that a person's life included a wide range of diversity activities and the actual relationship to the world. Family, school and social environment are the main external causes of influencing students' behavior, but what makes the urgency and necessity of strengthening setback education increasingly protrude is the lack of setback education in school and family education and setback education without proper guidance in society. Strengthening setback education not only can cultivate the perfect personality and healthy body but also the quality of bearing hardship and standing hard work. It is the responsibility among the society, schools and parents and needs three parties' together-work to achieve.

\section{REFERENCES}

[1] Husserl, the crisis of European sciences and transcendental phenomenology [M]. Shanghai: Shanghai translation publishing house, 1988-5.

[2] Jian-jun Feng, reflection and critique of the modernity of education, journal of nanjing normal university (social science edition) [J], 2004 (4) : 70-71.

[3] Yuan-qing Zhou. Construction of higher education powers - deal with construction of a well-off society in an all-round way $[\mathrm{J}]$, tsinghua university education research, 2003, (5) : 9-12.

[4] Da-wei Zhu/ Litao Lu, school curriculum management of peopleoriented education to explore [J], 2003 (9): 13, 14 and 15. 